Derecho \& Realidad

Núm. 21 • I semestre de 2013

Facultad de Derecho y Ciencias Sociales, UPTC

ISSN: 1692-3936

\title{
Reapropiación de bienes culturales $y$ derechos humanos
}

Reappropriation of cultural property and human rights

\author{
María Julia Ochoa Jiménez*
}

\section{Resumen}

En el debate sobre la repatriación de bienes culturales, siguen estando sobre la mesa las posiciones encontradas de quienes defienden su libre tráfico y quienes apuestan por su permanencia en su lugar de origen. Ubicándonos en este último grupo, sostenemos en el presente artículo que más allá de la repatriación como un proceso meramente jurídico-formal, el cual se encuentra basado en el contexto de latinoamericano, entre otras cosas, en la necesidad de una reparación poscolonial, desde la perspectiva de los derechos humanos es imperante garantizar a los grupos de origen la reapropiación de los bienes que sean repatriados.

\section{Palabras clave}

bienes culturales, derechos humanos culturales, repatriación cultural, reapropiación cultural.

\footnotetext{
* Máster en estudios jurídicos, Universidad de Navarra, Magistra iuris y Doctora en Derecho, GeorgAugust Universitaet Goettingen. Contacto mariajulia85@yahoo.com
} 


\begin{abstract}
In the debate on the repatriation of cultural property, the conflicting positions of those who defend its free trade and those who support its permanence in its place of origin, are on the table. This article can be situated in the latter group. It argues that beyond repatriation as a purely formal legal process, which in the context of Latin America is among other things based on the need for postcolonial reparation, from the human rights perspective, it is prevailing that the groups of origin ensure the reappropriation of those objects that are repatriated.
\end{abstract}

\title{
Key words
}

cultural property, human rights, cultural repatriation, reappropriation. 


\section{Introducción}

La restitución de bienes culturales a sus países de origen ha sido en las últimas décadas objeto de encendidos debates. Estos debates siguen moviéndose entre los dos extremos propuestos por Merryman (1986, p. 831-832), para distinguir entre quienes consideran que los bienes culturales son patrimonio común de la humanidad $\mathrm{y}$, en consecuencia, defienden su libre tráfico internacional (internacionalistas), y quienes consideran que los bienes culturales no deben ser separados definitivamente de la nación o grupo en el cual se han originado y que, si ello ha ocurrido, deben ser restituidos a la nación o grupo originario (nacionalistas). Este planteamiento de Merryman ha tenido un importante valor descriptivo y, en este sentido, ofrece un marco útil para el análisis de esta materia.

Siendo frecuente que los países de origen de objetos culturales exportados ilícitamente sean países no desarrollados o en vías de desarrollo y los países receptores sean países desarrollados, los ideales internacionalistas se han relacionado con la necesidad de investigación y de conservación de los objetos culturales extraídos. Así, resulta evidente la conveniencia del traslado de dichos objetos a países mejor preparados tecnológicamente y mejor equipados para tales fines y su permanencia en los mismos (Merryman, 1986, p. 846). Este argumento refleja claramente un discurso político que, a partir de la hegemonía de la ciencia, deslegitima a los países de origen considerándolos incapaces de "preservar y cuidar su propio pasado y su propia memoria” (Aguilar, 2011). Pero las razones esgrimidas para justificar la separación de los objetos culturales de sus lugares de origen no se han limitado históricamente a los fines de preservación e investigación. Las razones pueden ser muy variadas y de muy larga data. El saqueo de los pueblos conquistados por parte de los vencedores con el fin de entronizarse, además, como culturas vencedoras, ha sido práctica reproducida por diferentes pueblos a lo largo de la historia. Así mismo, el interés comercial que despiertan dichos bienes, aupado principalmente por el consumo de coleccionistas privados, ha sido también una causa importante facilitada por la actualmente creciente globalización económica.

La lucha por la restitución de bienes culturales, por su parte, es librada, como es natural, principalmente por los países de origen, o más precisamente, por grupos de origen (no siempre representados por los Estados, piénsese por ejemplo, en los pueblos indígenas). Esta lucha se basa en argumentos que, desde la perspectiva de Merryman, serían calificados como nacionalistas. Es así como se afirma que los bienes culturales solamente pueden cumplir su función originaria dentro del contexto cultural dentro del cual nacieron. Con otras palabras, dicha función originaria solo puede ser conocida, reconocida o reapropiada adecuadamente dentro del contexto cultural originario (Gerstenblith, 1995, p. 564; Moustakas, 1988, p. 1184). 
La lucha que describimos relaciona - o, más bien, opone - a países principalmente de origen con países tradicionalmente consumidores. Ha sido el caso de Egipto y Alemania $^{1}$, Grecia e Inglaterra ${ }^{2}$, Perú y Estados Unidos ${ }^{3}$, así como también de Ecuador e Italia ${ }^{4}$. Estos casos bien pueden calificarse como interestatales, aunque también se producen en el plano intraestatal. Por ejemplo, dentro de los Estados Unidos, país consumidor de bienes culturales extranjeros por excelencia, los pueblos indígenas han reclamado la restitución por parte de museos de objetos culturales de los cuales han sido despojados ilegítimamente y, justamente debido a ello, se dictó en 1990 una ley especial, la Ley de Protección y Repatriación de las Tumbas de los Nativos Estadounidenses o Native American Graves Protection and Repatriation Act (NAGPRA) $)^{5}$.

En América Latina, como en otras partes del mundo, en los últimos años el interés por la restitución de bienes culturales (principalmente, bienes arqueológicos) pone sobre el tapete la legitimidad —o, más bien, ilegitimidad — de las extracciones y las

Las demandas de restitución del Busto de Nefertiti son conocidas por el mundo entero. Estas demandas no son recientes: comenzaron cuando se hizo público por primera vez, en 1924, que el busto se encontraba en el Museo de Berlín. Sin embargo, son continuamente reseñadas por la prensa. En una conferencia en el año 2005, Kurt Siehr, del Instituto Max Plank de Derecho Internacional Privado, argüía a favor de la restitución del busto a Egipto, basándose en la conveniencia de exhibir el busto en su contexto originario y en el apoyo que la devolución daría a Egipto en tanto país aún en recuperación del imperialismo (O’Connell, 2005, p. 489). En el contexto actual posterior a la primavera árabe son menos frecuentes este tipo de declaraciones.

2 Al hablar de restitución de bienes culturales, el caso de los mármoles del Partenón es el más referido por la literatura y la prensa. Entre 1801 y 1812, Thomas Bruce, conocido como Lord Elgin, embajador inglés ante el imperio otomano desde 1799 hasta 1803, removió de Grecia y transportó hasta Inglaterra una buena parte de los restos del Partenón. En 1816, Lord Elgin vendió los mármoles al Museo Británico, donde todavía se encuentran. Mucho se ha discutido sobre la legalidad tanto de la remoción de los mármoles por parte de Lord Elgin como de su transmisión al Museo Británico, así como también sobre la conveniencia de que los mismos permanezcan en Inglaterra en lugar de ser retornados a Grecia.

3 El gobierno de Perú reclama a la Universidad de Yale la restitución de 46.332 objetos originarios de Machu Picchu que en 1911 fueron trasladados a los Estados Unidos por Hiram Bingham. En 2005, Perú inició negociaciones a nivel diplomático, pero en 2009 fue interpuesta demanda ante los tribuales estadounidenses en contra de la mencionada universidad.

4 Si bien Italia es un país de origen de muchos objetos culturales que se encuentran fuera de sus fronteras, el caso Ecuador vs. Danusso ha sido especialmente relevante desde el punto de vista jurídico. En 1982, un tribunal italiano decidió que eran aplicables tanto la prohibición de exportación como la inalienabilidad derivada del "dominio eminente" establecido a favor del Estado por la legislación ecuatoriana entonces vigente. En consecuencia, los derechos sobre 12.000 objetos históricos y arqueológicos que, supuestamente de buena fe, habían sido adquiridos en Ecuador y transportados a Italia por el ciudadano italiano Danusso entre 1972 y 1975 , y que habían sido decomisados por las autoridades italianas, fueron reconocidos a favor de Ecuador (Turner, 2002, p. 91; Weidner, 2001, p. 93)

5 Public Law 101-601, Stat. 104 3048, aprobada el 16 de noviembre de 1990. Legislaciones como NAGPRA -otra legislación similar existe en Nueva Zelandia- son más bien excepcionales. En este contexto, es de resaltar, además, que el ámbito de acción de la UNESCO se restringe a la actuación de cada Estado en tanto Estado-Nación, de manera que los conflictos intraestatales de este tipo escapan de su competencia (Bauer, 2008, p. 703-704). 
transferencias de bienes que hoy se encuentran en el extranjero, al tiempo que se aboga por su retorno.

Hoy los debates y negociaciones en torno a la restitución de bienes culturales tienen lugar en una atmósfera con ciertas particularidades. Actualmente se dispone de foros internacionales (v. gr. UNESCO), de ciertos estándares internacionales (documentos emanados de dichos foros, tales como declaraciones y recomendaciones) y de algunas normas de obligatorio cumplimiento para los Estados que ratifican los tratados que las contienen, como es el caso de la Convención de la UNESCO sobre las medidas que deben adoptarse para prohibir e impedir la importación, la exportación y la transferencia de propiedad ilícitas de bienes culturales, de 1970 (Convención UNESCO de 1970) y la Convención de la UNIDROIT sobre bienes culturales robados o exportados ilícitamente, de 1995 (Convención UNIDROIT de 1995), todo lo cual ha configurado un ambiente normativo en buena medida favorable a la restitución de bienes ilegalmente extraídos de sus países de origen y trasladados a otros países. Particularmente interesante en la Convención UNIDROIT de 1995 es que esta dispone que un objeto cultural que haya sido ilícitamente extraído, una vez repatriado, habrá de regresar a la comunidad indígena o tribal cuando haya sido creada por esta para usos tradicionales (artículo 7).

Sin embargo, en el contexto que hemos expuesto sale a flote la idea de que, además del deber de realizar los esfuerzos necesarios para lograr la repatriación de los bienes culturales que han dejado ilícitamente su lugar de origen, recae principalmente sobre el Estado (aunque también sobre otros actores) una obligación frente a la sociedad en general y, particularmente, frente a los grupos de origen, en relación con lo que en este artículo denominamos reapropiación cultural de los objetos culturales repatriados. En efecto, la recuperación física de los objetos culturales no puede ser vista aisladamente, es decir, como un procedimiento meramente jurídicoformal. Existe, por el contrario, una obligación estatal que, en virtud de ciertos derechos humanos, tiene por fin garantizar que dichos objetos puedan ser reapropiados culturalmente por la sociedad originaria en general o, en su caso, por el grupo originario particular que ha sufrido la ausencia de objetos que son importantes para su cultura.

En el presente trabajo presentamos algunas reflexiones sobre cuál ha de ser el contenido y alcance de la reapropiación cultural como obligación de los Estados de origen que exigen la devolución de objetos culturales. Antes de exponer dichas reflexiones, será necesario, no obstante, referirse a ciertos aspectos generales sobre la repatriación de bienes culturales, presupuesto necesario para que pueda producirse la reapropiación cultural de los mismos. 


\section{La repatriación de bienes culturales}

Se entiende aquí la repatriación como un concepto amplio que abarca las diversas formas en las que puede darse el retorno de bienes culturales que se encuentran fuera de su lugar de origen. Así entendida, la repatriación puede adoptar al menos las formas que seguidamente mencionamos.

La primera de ellas es la del retorno que se efectúa teniendo como marco la Convención UNESCO de 1970. Esta Convención, en aplicación directa de su artículo 9, puede facilitar una repatriación negociada (lo que ocurrió, por ejemplo, con los $q^{\prime}$ ipis que, siendo originarios de Bolivia, habían sido llevados ilícitamente a los Estados Unidos) $)^{6}$, o servir de base para la celebración de acuerdos entre Estados para el control del tráfico ilícito entre ellos, como ha sido el caso de los memorandos de entendimiento celebrados por los Estados Unidos con diferentes países y de los acuerdos bilaterales existentes entre varios países latinoamericanos.

En segundo lugar, el término repatriación abarca el retorno ordenado, de un lado, por un juez nacional del país receptor, lo cual puede ocurrir por aplicación de la Convención UNIDROIT de 1995, la cual, una vez firmada y ratificada, debe ser aplicada directamente en territorio del país que la ha firmado y ratificado ${ }^{7}$. Quedan, así, comprendidas la devolución (en caso de bienes robados) y la restitución (en caso de bienes exportados en contravención al derecho interno del país de origen) establecidas por esta Convención UNIDROIT de 1995. De otro lado, este término también se refiere a la devolución que tiene lugar con motivo de una disputa internacional (como ha ocurrido en la Corte Internacional de Justicia, ante la cual han sido llevados algunos casos) $)^{8}$.

La repatriación abarca, en tercer lugar, el retorno de bienes culturales producto de la utilización del derecho internacional privado, por aplicación de normas civiles o normas especiales sobre patrimonio cultural del país del foro, es decir, el país donde se encuentra el bien, el país donde se haya producido la compraventa,

6 Los q'ipis son tejidos sagrados de una comunidad indígena ecuatoriana que durante los años noventa fueron objeto de tráfico ilícito. Algunos tejidos fueron regresados a la comunidad desde los Estados Unidos, a donde habían sido llevados por un traficante, quien posteriormente hizo llegar algunos de ellos a Canadá, desde donde también fue recuperada una parte de los tejidos que habían sido robados de la comunidad. El caso de los tejidos devueltos desde Estados Unidos se resolvió por acuerdo extrajudicial y por apoyo entre autoridades ecuatorianas y estadounidenses, mientrasque la devolución de los q'ipis que habían sido llevados a Canadá se debió a orden judicial (para mayor información se recomienda Lobo, 1991).

7 Los Estados partes de la Convención UNIDROIT de 1995 son en su mayoría países de origen.

8 Por ejemplo, los casos que han involucrado a Camboya y Tailandia (Prea Vihear) y a países de la ex Yugoslavia (Bosnia y Herzegovina vs. Serbia y Montenegro, Croacia vs. Servia). 
etc. Esto ocurrió, por ejemplo, en el caso de los q'ipis que fueron devueltos desde Canadá9.

Por último, la repatriación puede darse en el contexto de procesos basados en la negociación por parte de instituciones del país de origen frente a instituciones del país donde el bien cultural respectivo se encuentra, sin que medien necesariamente normas jurídico-positivas que les den respaldo. Entrarían dentro de este grupo las normas de soft law (importantes en todo caso a la hora de interpretar algunas normas de hard law, como sería el caso de algunas normas de la Convención Americana sobre Derechos Humanos), entre las cuales es de importancia en este contexto la Declaración de las Naciones Unidas sobre los Derechos de los Pueblos Indígenas del 2007 (DNUDPI) que establece que estos pueblos tienen el derecho a practicar y revitalizar sus costumbres y tradiciones culturales, así como también a que los Estados les restituyan, en términos establecidos conjuntamente con ellos mismos, los bienes culturales de que hayan sido privados sin su consentimiento libre, previo e informado o en violación de sus leyes, tradiciones y costumbres (artículo 11).

Cada proceso, así como los actores que hacen parte del mismo, varían en cada uno de los tipos de repatriación. En un contexto judicial nacional, por ejemplo, el proceso será un proceso judicial regido por las normas del país en el que el mismo tiene lugar, contando con la participación de un particular, ya sea como poseedor no legítimo o como propietario legítimo no poseedor y, por tanto, reclamante de la devolución, sin que sea imprescindible la participación del Estado en tanto parte del proceso. En el ámbito supranacional, cuando se trata de la aplicación de tratados internacionales, la regla general es, por el contrario, que la disputa se produzca con participación del Estado.

En este contexto, es importante hacer hincapié en que, cualquiera sea la forma de repatriación que haya sido usada por el Estado de origen (o por otro sujeto) para lograr que los bienes culturales extraídos ilícitamente vuelvan a su lugar originario, a dicha repatriación debe seguir un proceso de reapropiación cultural, entendido como una obligación que recae principalmente sobre los hombros del Estado de origen. Así mismo, debe considerarse lo anterior tomando particularmente en cuenta el hecho de que contemporáneamente las normas sobre derechos humanos exigen de los Estados el reconocimiento de derechos de los grupos a su patrimonio cultural.

\footnotetext{
9 Roger Yorke fue juzgado de acuerdo con la ley canadiense, encontrado culpable de importación ilícita y condenado a la entrega de los bienes confiscados, entre ellos algunos tejidos ( $\left.q^{\prime i} i p i s\right)$ de Coroma. El caso de los tejidos de Coroma ha sido considerado como uno más en el que para evadir la ley canadiense se ingresan bienes culturales a través de los Estados Unidos. Los tejidos que fueron recuperados en Canadá -cerca de cuarenta- fueron devueltos en el 2002 a Bolivia (sobre este caso puede consultarse Paterson, 1993).
} 


\section{La reapropiación cultural de bienes culturales repatriados}

Se ha afirmado que la reapropiación cultural constituye una obligación del Estado de origen exigida por el hecho de la repatriación. Esta afirmación tiene diversas implicaciones que a continuación pasamos a analizar. Se trata, ante todo, de una obligación del Estado que nace en el momento en que se manifiesta la voluntad de exigir o solicitar la repatriación. El Estado que reclama la repatriación de un bien cultural lo hace con la convicción de que su reclamación es legítima, aunque no siempre esta legitimidad estará basada en normas jurídico-positivas, pues muchos son los casos en los cuales no se dispone de normas legales que les den respaldo. Así ocurre actualmente, por solo mencionar un ejemplo, en las reclamaciones que hace Turquía al Metropolitan Museum of Art de Nueva York. Trátese o no de una reclamación con base en disposiciones legales, al considerar legítima su reclamación, el Estado reclamante actúa como "legítimo propietario" del bien reclamado. Dicha "legítima propiedad", sin embargo, es (ya por disposición legal, ya por consideraciones extralegales) una propiedad colectiva cuyo titular es o bien la nación, o bien un grupo particular, por ejemplo, el pueblo indígena en cuyo seno ha sido creado el objeto cultural en cuestión o sus descendientes. En este sentido puede mencionarse cómo en el sistema interamericano, mediante interpretación evolutiva del derecho de propiedad contenido artículo 21 de la Convención Americana de Derechos Humanos, se ha reconocido la relación de este derecho con la identidad cultura de los pueblos indígenas. En efecto, al reconocer que existe un corpus iuris ${ }^{10}$ que define las obligaciones de los Estados para la protección de los derechos de propiedad indígenas, se han protegido al mismo tiempo formas tradicionales de propiedad relacionadas con su supervivencia cultural. (Comisión Interamericana de Derechos Humanos 2009, párrafos 6 y sig.).

En este orden de ideas, el Estado no puede legítimamente privar del bien a la colectividad general o, en su caso, al grupo particular, lo cual no deja de ocurrir al ser el bien cultural confinado a las vidrieras de un museo nacional o los laboratorios de un instituto de investigación. Antes bien, habiendo exigido la devolución de un objeto cultural y habiendo sido esta exitosa, será necesario que la colectividad o, en su caso, el grupo de origen del objeto cultural respectivo pueda reapropiarse del mismo una vez repatriado, objeto del que estuvo privado de forma ilegítima. Solamente así serán atendidas las circunstancias que han sido las razones en las que se ha basado la reclamación del Estado (la legítima propiedad).

Ahora bien, partiendo de la existencia de esa obligación es necesario considerar en qué consiste la misma, es decir, qué es lo que está llamado a hacer (o no hacer) el

10 Los instrumentos principales que componen este corpus iuris son el Convenio 169 de la OIT y la DNUDPI. 
Estado en virtud de ella. Antes de pasar a dichas consideraciones, conviene, no obstante, distinguir nuestro planteamiento de otro al cual se relaciona de manera muy cercana. En efecto, un planteamiento que merece ser tomado en cuenta, puesto que compartimos en su totalidad, es el que ve el retorno de los bienes culturales (particularmente los bienes arqueológicos) a su lugar de origen como una reparación, específicamente como una reparación postcolonial que, a partir de la necesidad de "subsanar la herida colonial a partir de la posesión del propio pasado y la preservación de la memoria colectiva de los pueblos", estima oportuno que exista un "proyecto político que reconozca la legitimidad de las comunidades descendientes en la posesión y manejo de su propia materialidad con la misma legitimidad tanto de las instituciones del primer mundo como de las instituciones nacionales" (Aguilar, 2011, p. 230). Como puede apreciarse claramente, este planteamiento presupone la existencia de un daño, de una injusticia infligida por un sujeto a otro, de tal manera que nace la necesidad de corrección o reparación. Así sale a relucir que tras dicho planteamiento subyace la idea de justicia aristotélica en su dimensión correctiva o retributiva. En efecto, si se ha tenido lugar el acceso por parte de un tercero al patrimonio cultural originario de una comunidad determinada sin el consentimiento de esta, entonces se produce ciertamente un acto lesivo, de desposesión. Esto hace nacer la necesidad de corrección, es decir, la reparación del daño causado. Así mismo, este planteamiento considera la existencia de la obligación histórica o deuda histórica que tienen los países colonizadores, generalmente receptores de bienes culturales de pueblos colonizados, frente a estos pueblos cuyas condiciones de vida actuales han sido, además, modeladas por la conquista y la colonización y por diversas circunstancias sucesivas producidas como consecuencia de tales procesos (Ochoa, 2010). En esta misma línea se encuentra la idea de "reparaciones por pérdida cultural" de los pueblos indígenas producida en un contexto de colonización, de la cual habla Vrdoljak (2008 y 2011).

El presente artículo no pretende, sin embargo, escudriñar en las razones que justifican la repatriación sino que, partiendo de la existencia de la práctica por lo general meramente jurídico-formal (y, por tanto, insuficiente) de la repatriación de los bienes culturales, busca aproximarse, a partir del derecho internacional de los derechos humanos, al contenido y alcance de la obligación de reapropiación cultural de objetos repatriados, obligación que ha de ser considerada necesariamente en el contexto reparatorio o restitutivo que describe el anterior planteamiento.

\section{Derechos humanos: contenido y alcance de la reapropiación cultural como obligación estatal}

En el contexto descrito, es de interés considerar ciertas bases jurídicas que dan sustento a la obligación que recae sobre el Estado y que debe materializarse una vez producida la repatriación de un bien cultural. Dichas bases jurídicas se encuentran en 
determinados derechos contenidos en instrumentos de derechos humanos: el derecho de participación en la vida cultural, en el sentido de acceso al patrimonio cultural y a su disfrute, en su relación con el derecho a la autodeterminación cultural y el principio de igualdad. Tales derechos habrán de ser vistos, en todo caso, tomando igualmente en cuenta los siguientes derechos: el derecho de participar en la vida cultural, el derecho de los integrantes de las minorías a disfrutar de su propia cultura y el derecho de los pueblos indígenas a la libre determinación y a mantener, controlar, proteger y desarrollar el patrimonio cultural, así como también derechos humanos de contenido más general, como los derechos a la libertad de expresión, la libertad de conciencia y religión, el derecho a la información y el derecho a la educación. (Consejo de Derechos Humanos de la ONU 2010, párrafo 78).

En este contexto, la obligación de repatriación tiene como contenido la creación y el fortalecimiento de ciertas condiciones que serán las que harán posible la efectiva reapropiación cultural del bien repatriado por parte de la comunidad o el grupo respectivo. Las condiciones a las que nos referimos no se limitan a aquellas necesarias para la preservación de los bienes culturales en sí o de las expresiones culturales de ellos encarnan, entendidos únicamente como materialidades. Tampoco se refieren a las condiciones necesarias para el acceso material al bien repatriado por parte de la comunidad, por ejemplo, mediante su exhibición en un museo. Dichas condiciones han sido bien estudiadas (a pesar de que su implementación no es tarea sencilla) y están bastante claramente establecidas por las leyes. De lo que se trata aquí es de la necesidad de garantizar los dos tipos de condiciones siguientes. En primer lugar, han de crearse o fortalecerse, cuando sea posible, las condiciones que permitieron la creación y el desarrollo del bien cultural repatriado, es decir, las condiciones predominantes en el grupo cultural de origen al momento de producirse la extracción ilegítima del bien respectivo (condiciones originarias). Cuando ello no sea posible, habrán de ser garantizadas las condiciones que permitan la creación o el desarrollo de nuevos bienes o manifestaciones culturales que se relacionen de alguna manera con el bien repatriado (condiciones no originarias).

Lo anterior puede ayudar a comprender mejor la idea de que existen múltiples patrimonios culturales, lo que se evidencia al observarlos desde la óptica de los derechos humanos. Así, la dimensión humana hace que estos no sean vistos solo como materialidades con importancia sobresaliente para el mundo o para el país, sino también como manifestaciones culturales que son importantes para una comunidad concreta, muy especialmente cuando solo en esa comunidad el objeto puede cumplir su función cultural. Esto es importante especialmente si enfatizamos el hecho de que tradicionalmente la tarea de definir qué es patrimonio cultural ha sido secuestrada, en buena medida mediante legislación, por las instituciones oficiales nacionales e internacionales, bajo un complejo de relaciones de poder existentes entre diferentes sujetos: instituciones del Estado, autoridades locales, expertos, 
académicos, empresarios, propietarios públicos o privados, asociaciones civiles, comunidades y sus miembros. (Consejo de Derechos Humanos de la ONU, 2010, párrafos 7 y 10).

Es así como en estas relaciones de poder la preeminencia del más poderoso se traduce en el desarrollo de procesos políticos y la formación de opinión pública que conducen a un acercamiento o un alejamiento de poblaciones y comunidades. Particularmente la limitación del acceso al patrimonio cultural y su disfrute, como lo ha afirmado la Experta independiente en la esfera de los derechos culturales del Consejo de Derechos Humanos de la ONU, puede utilizarse como instrumento de presión política o social (Consejo de Derechos Humanos de la ONU, 2010, párrafo 10). Así, comunidades y pueblos son tratados como un medio y no como un fin, con lo cual se hace evidente una vulneración de la dignidad de estos grupos.

En este contexto, los Estados suelen afirmar en el plano internacional que existen mecanismos que permiten la participación de las comunidades en la determinación del patrimonio protegido y en las políticas para su conservación y salvaguarda ${ }^{11}$. Sin embargo, en la mayoría de los casos la decisión final sobre estos temas fundamentales recae sobre el Estado sin que en ella se refleje necesariamente la participación de las comunidades o pueblos concernidos. En ausencia de dicha participación no es posible el desarrollo de las condiciones a través de las cuales se materialice la reapropiación cultural de bienes culturales repatriados.

Volver a las condiciones originarias es muy difícil (en cierto sentido, podría decirse que el caso de los $q^{\prime}$ ipis que fueron devueltos a la comunidad Coroma de Bolivia se puede considerar un ejemplo de ello ${ }^{12}$, de allí que la regla general sea la imposibilidad de volver a la situación anterior a la extracción ilícita del objeto. En su obligación de garantizar la reapropiación cultural, el Estado procurará, entonces, principalmente que se creen o se fomenten condiciones no originarias. Las condiciones no originarias deben permitir a la comunidad de origen re-conocer, re-comprender y re-aprehender los bienes culturales repatriados. Solamente mediante esta interrelación de la comunidad originaria con el objeto cultural que ha sido repatriado será posible la recreación constante del mismo, elemento esencial de los patrimonios culturales (Consejo de Derechos Humanos de la ONU, 2010, párrafo 7).

El re-conocimiento, la re-comprensión y la re-aprehensión de que hablamos se realizan en el marco de ciertos derechos humanos, que les sirven de referentes

\footnotetext{
11 Véanse, por ejemplo, las respuestas a la encuesta realizada en el 2010 por la experta independiente en la esfera de los derechos culturales del Consejo de Derechos Humanos de la ONU.

12 Aunque la larga separación de los tejidos de la comunidad dejó secuelas importantes. Para mayor información ver notas pie de página 6 y 9 y bibliografía recomendada.
} 
normativos y conceptuales y, al mismo tiempo, son estos derechos humanos los que constituyen el contenido específico de la obligación estatal de reapropiación cultural. Los derechos humanos a que hacemos referencia son, como hemos apuntado, el derecho de participación en la vida cultural, en el sentido de acceso al patrimonio cultural y a su disfrute, y el derecho a la autodeterminación cultural, ambos a la luz del principio de igualdad. Así, el acceso y el disfrute del patrimonio repatriado deben garantizarse sin discriminación, particularmente sin discriminación en razón de la identidad cultural de las personas. De qué manera intervienen estos derechos en la configuración de la obligación de reapropiación cultural que aquí nos interesa, es lo que nos ocupará en seguida.

En esta materia convergen derechos establecidos en instrumentos de derechos humanos y en instrumentos específicos sobre patrimonio cultural (Convenciones de la UNESCO) y, tratándose de bienes culturales indígenas, particularmente derechos contenidos en instrumentos sobre derechos indígenas (la DNUDPI y el Convenio 169 de la OIT sobre Pueblos Indígenas y Tribales). Debe recordarse, ante todo, que los derechos humanos son universales, indivisibles e interdependientes y que una parte del sistema de los derechos humanos son los derechos culturales (Comité de Derechos Económicos, Sociales y Culturales, 2010). Así, pues, que tratar de realizar un estudio de algún derecho humano aislado, separado de otros derechos humanos, trae consigo el riesgo de una fragmentación que no sólo no es conveniente, sino que además no es posible. Los derechos que hemos mencionado más arriba se interrelacionan en el sentido de que solamente a través del ejercicio del derecho a la participación y del derecho a acceder y contribuir a la vida cultural es posible la materialización del derecho a la autodeterminación cultural. Así mismo, el ejercicio de estos dos derechos debe estar, en este contexto como en cualquier otro, regido por el principio de igualdad (artículos 2.2 y 3 del Pacto Internacional sobre Derechos Económicos Sociales y Culturales (PIDESC), el artículo 2 de la DNUDPI y el artículo 3 del Convenio 169 de la OIT).

El derecho a participar en la vida cultural se encuentra en el artículo 15, párrafo 1a) del PIDESC y en el párrafo 1 del artículo 27 de la Declaración Universal de Derechos Humanos (DUDH) ${ }^{13}$. Este derecho ha sido entendido como una libertad (o, más concretamente, como un conjunto de libertades $)^{14} \mathrm{y}$, en este sentido, implica

13 Otras convenciones contienen también este derecho, aunque con ciertos matices. Al respecto se pueden ver: la Convención Internacional sobre la Eliminación de todas las Formas de Discriminación Racial, artículo 5, apartado e) vi); la Convención sobre la Eliminación de todas las Formas de Discriminación contra la Mujer, artículo 13, apartado c); la Convención sobre los Derechos del Niño, artículo 31, párrafo 2; la Convención Internacional sobre la Protección de los Derechos de todos los Trabajadores Migratorios y de sus Familiares, artículo 43, párrafo $1 \mathrm{~g}$ ); la Convención sobre los Derechos de las Personas con Discapacidad, artículo 30, párrafo 1.

14 Ver, por ejemplo, la Declaración de Friburgo (2007, artículo 5). 
tanto un deber de abstención como un deber de realización de medidas positivas por parte del Estado. Estas obligaciones suelen describirse como obligaciones de respetar, proteger y cumplir (Consejo de Derechos Humanos de la ONU 2010, párrafos 65 y sig.). Particularmente en cuanto a los pueblos indígenas, la DNUDPI expresamente indica que "los Estados establecerán mecanismos eficaces para la prevención y el resarcimiento de (...) [t] odo acto que tenga por objeto o consecuencia privarlos de su integridad como pueblos distintos o de sus valores culturales o su identidad étnica" (artículo 8.2).

Esta dimensión del derecho de participación en la vida cultural como conjunto de libertades es relevante como contenido de la obligación de reapropiación cultural de bienes culturales que sean repatriados. Dicha dimensión hace recaer sobre el Estado el deber de crear condiciones que permitan el acceso a los bienes culturales, pero ello no se limita a la consideración de estos bienes como materialidades, aunque bien es cierto que "considerar el acceso al patrimonio cultural y su disfrute como un derecho humano es un criterio necesario y complementario de la preservación y salvaguardia del patrimonio cultural", como ha dicho la Experta independiente en la esfera de los derechos culturales de la ONU (Consejo de Derechos Humanos de la ONU 2010, párrafo 2).

Una importante aclaración que hace la Observación General 21 del Comité de Derechos Económicos, Sociales y Culturales (Comité DESC) se refiere al hecho de que la libertad de participar de la vida cultural se ejerce mediante una elección (la de participar o no participar) que es una elección cultural. Ello quiere decir que no se trata de una elección cualquiera, sino que de ella participan consideraciones que exceden la esfera exclusiva de las personas, ya sea como sujeto individual o como miembro de un sujeto colectivo. Al tener este derecho como contenido, el deber de reapropiación comprende, igualmente, la idea de los objetos culturales como producto social, con lo que se hace patente el hecho de que la comunidad de origen de un bien cultural repatriado no es bajo ninguna circunstancia un mero "usuario" del bien cultural, visión que en buena medida parece aún predominar entre las instituciones culturales nacionales (por ejemplo, los museos).

Las comunidades de origen no son algo abstracto, amorfo, pues están constituidas por personas, y las expresiones cultuales expresadas en objetos culturales que son producto de esa colectividad o esos individuos, se insertan en un "proceso vital, histórico, dinámico y evolutivo" (Comité de Derechos Económicos Sociales y Culturales, 2010, párrafo 11), que no es otro que el proceso vital de la propia comunidad. Siendo el bien cultural repatriado un producto social en el sentido expuesto, el derecho a la reapropiación del objeto cultural repatriado supone el ejercicio del derecho individual y colectivo (Consejo de Derechos Humanos de la 
ONU, 2011, párrafo 61) ${ }^{15}$ a participar en el desarrollo de la propia comunidad, lo cual implica necesariamente la participación en la definición, formulación y aplicación de políticas y decisiones que incidan en el ejercicio de sus derechos culturales dentro de ese contexto (Comité de Derechos Económicos Sociales y Culturales 2010, párrafos 11 y 15).

Esto no supone, sin embargo, exclusión de otros sujetos, distintos de la comunidad de origen y sus miembros. Este derecho a la repatriación no desconoce que toda persona tiene también derecho a conocer formas de expresión de las diferentes culturas - para lo cual han de ser difundidas por cualquier medio tecnológico de información y comunicación-, así como también a beneficiarse del patrimonio cultural y de las creaciones de otros individuos y comunidades, pues el derecho de acceso a la cultura implica el derecho a tener acceso al patrimonio cultural propio y al patrimonio cultural de otros. En este sentido, no debe olvidarse que existe una relación fundamental entre el conocimiento y reconocimiento de las diversas identidades culturales de individuos y comunidades y la eliminación de la discriminación, directa o indirecta, de minorías o pueblos indígenas (Comité de Derechos Económicos Sociales y Culturales 2010, párrafos 15, 23, 32, 36).

Pero es evidente que no todos los sujetos tienen el mismo grado de interés en los bienes culturales específicos. Es así como el interés que tiene la comunidad de origen en los objetos culturales originados en su seno prevalece frente a otros intereses.

Para comprender qué es una comunidad de origen debe distinguírsele de lo que se ha llamado "comunidad patrimonial", es decir, aquella "que está integrada por personas que valoran aspectos específicos del patrimonio que, en el marco de la acción pública, quieren mantener y transmitir a futuras generaciones" (Comité de Derechos Económicos Sociales y Culturales, 2010, párrafo 62).

La comunidad de origen no solamente valora el bien cultural y desea transmitirlo a las futuras generaciones, sino que es capaz de mantenerlo vivo por ser éste parte integrante de la misma vida de la comunidad.

Cuando un objeto cultural ha sido extraído de su lugar de origen en una comunidad particular, permaneciendo lejos por un tiempo considerable, la posibilidad de que

$\overline{15}$ El derecho humano de acceso al patrimonio cultural es un derecho tanto individual como colectivo, tal como lo establece la DNUDPI. Es un derecho cuyo titular puede ser una persona como individuo, en asociación con otras personas o dentro de una comunidad o grupo (Comité de Derechos Económicos Sociales y Culturales, 2010, párrafo 9; Vrdoljak, 2012). 
el vínculo entre la comunidad de origen y el bien se rompa es mayor que cuando el bien se encuentra todavía en ese lugar. Así, está en mayor riesgo tanto la preservación cultural del bien repatriado (más allá de la preservación del bien cultural como materialidad), como la forma de vida y expresión de la propia comunidad. Esto subraya la obligación del Estado de garantizar la participación de las comunidades de origen del bien cultural repatriado, esto es, de personas pertenecientes a minorías, pueblos indígenas u otras comunidades, en la formulación y aplicación de las leyes y las políticas que les conciernen (Comité de Derechos Económicos Sociales y Culturales 2010, párrafos 36).

Garantizar la participación en la vida cultural de la manera expuesta es, además, un medio para asegurar la no asimilación de las comunidades no dominantes o no mayoritarias dentro de las comunidades o sociedades dominantes o mayoritarias (lo cual es exigido por el artículo 8.1 de la DNUDPI) ${ }^{16}$. En efecto, el riesgo de asimilación se acentúa cuando los objetos que han sido repatriados son confinados a las salas de museos o institutos de investigación sin tomar en cuenta la participación de comunidades, sus creencias, sus opiniones (Consejo de Derechos Humanos ONU, 2011, párrafo 18), quedando así completamente vacía a la repatriación, incluso considerada ésta como hecho compensatorio, puesto que no pasa de ser un proceso jurídico-formal.

Lo dicho pone de manifiesto la clara relación que existe entre el derecho a la participación en la vida cultural, en el sentido de acceso al patrimonio cultural y a su disfrute, y el derecho a la autodeterminación cultural y el principio de igualdad, toda vez que el derecho a la autodeterminación cultural consiste en el derecho de personas y grupos a escoger su sistema cultural y forjar libremente su desarrollo cultural y a recuperar, disfrutar y enriquecer su patrimonio cultural. En el caso de los pueblos indígenas esto se inserta en su derecho a la libre determinación, en virtud del cual "determinan libremente su condición política y persiguen libremente su desarrollo económico, social y cultural” (artículo 3 de la DNUDPI). Ello comprende el derecho a seguir un estilo de vida que se encuentra asociado al uso de recursos como la tierra, el agua, la biodiversidad, el lenguaje o instituciones específicas, así como también a determinados bienes culturales de los que han sido despojados. Es así como puede afirmarse, en fin, que resulta perfectamente claro que la obligación de reapropiación de bienes culturales repatriados en el sentido expuesto, se encuentra enmarcada en el sistema de los derechos humanos culturales.

\footnotetext{
16 El artículo 8.1 de la DNUDPI dice: "Los pueblos y los individuos indígenas tienen derecho a no ser sometidos a una asimilación forzada ni a la destrucción de su cultura".
} 


\section{Lista de Referencias}

Aguilar, M. (2011). Entre diálogos y repatriaciones. Reparación colonial por la memoria y preservación de Machu Picchu. Antípoda. Revista de Antropología y Arqueología, (12), 211-234.

Bauer, A. (2008). New ways of thinking about cultural property: a critical appraisal of the antiquities trade debates. Fordham International Law Journal, (31), 690-724.

Comisión Interamericana de Derechos Humanos. (2009). Documento OEA/Ser.L/ V/II. Derechos de los Pueblos Indígenas y Tribales sobre sus Tierras Ancestrales y Recursos Naturales. Recuperado de http://www.oas.org/es/ cidh/indigenas/docs/pdf/Tierras-Ancestrales.ESP.pdf.

Comité de Derechos Económicos Sociales y Culturales. (2010). Documento E/ C.12/GC/21/Rev.1. Observación General 21, Derecho de toda persona a participar en la vida cultural (artículo 15, párrafo 1 a), del Pacto Internacional de Derechos Económicos, Sociales y Culturales. Recuperado de http:// www2.ohchr.org/english/bodies/cescr/comments.htm.

Consejo de Derechos Humanos ONU. (2011). Documento A/HRC/17/38. Informe de la experta independiente en la esfera de los derechos culturales, Sra. Farida Shaheed. Recuperado de http://daccess-dds-ny.un.org/doc/UNDOC/ GEN/G11/122/07/PDF/G1112207.pdf?OpenElement.

Gerstenblith, P. (1995). Identity and cultural property: The protection of cultural property in the United States. Boston University Law Review, (75), 559-688.

Lobo, S. (2009). The Fabric of Life: Repatriating the Sacred Coroma Textiles. Cultural Survival Quarterly. 3 (15), 40-46.

Merryman, J. (1986). Two ways of thinking about cultural property. American Journal of International Law, (80), 831-853.

Moustakas, J. (1980). Group rights in cultural property: Justifying strict inalienability. Cornell Law Review, (74), 1179-1227.

Ochoa, M. (2010). Patrimonio cultural indígena: normatividad internacional y justicia. En: M.Tosta \& A. Uzcátegui. Estudios en homenaje a Mariano Uzcátegui Urdaneta. Venezuela: Universidad Central de Venezuela y Universidad de Los Andes.

O'Connell, M. \& DePaul, S. (2005). Report on the Conference: Imperialism, Art and Restitution. International Journal of Cultural Property. 4 (1), 487-490. 
Paterson, R. (1993). Bolivian Textiles in Canada. International Journal of Cultural Property, 2 (2), 359-370.

Turner, S. (2002). Das Restitutionsrecht des Staates nach illegaler Ausfuhr von Kulturgütern: Eigentumsordnung und völkerrechtliche Zuordnung. Berlin: De Gruyter.

Vrdoljak, F. (2008). Reparations for Cultural Loss. Retrieved from http:// works.bepress.com/ana_filipa_vrdoljak/1. [Consultado el 30 de octubre de 2012].

Vrdoljak, F. (2011). Restitution of Cultural Properties Trafficked During Colonization: A Human Rights Perspective. Retrieved from http:// works.bepress.com/ana_filipa_vrdoljak/22.

Weidner, A. (2001). Kulturgüter als res extra commercium im internationalen Sachenrecht. Berlin: De Gruyter. 